\title{
Economic literacy and the war on poverty: a social work challenge?
}

\author{
Engelbrecht L. Economic literacy and the war on poverty: \\ a social work challenge? \\ Int J Soc Welfare 2008: 17: 166-173 (C) 2008 The Author(s), \\ Journal compilation (C) 2008 Blackwell Publishing Ltd and the \\ International Journal of Social Welfare.
}

This article reports on an exploratory descriptive study that examined ten social workers' perceptions of their war on poverty and the challenges in constructing a conceptual framework for the development of a Social Community Education for Economic Literacy Development (SCEELD) programme. It was found that the social workers were knowledgeable about the uneconomic activities of their clients and that their ideas about what needed to be done about this related very much to their attitudes towards poverty. Significantly, the social workers did not think that job creation was their primary responsibility nor had, in their experience, job creation programmes been successful. Rather, the economic literacy they taught related to housekeeping imperatives, such as economical food preparation and managing income and concrete resources no matter how meagre. Overall, the social workers did not perceive the agency culture or the context of developmental welfare practice as conducive to the implementation of programmes aimed at economic development, and none talked about the relationship between economic and social development.

\section{Lambert Engelbrecht}

University of Stellenbosch, South Africa

Key words: economic literacy, poverty, social work, South Africa

Lambert Engelbrecht, Arts Building, University of Stellenbosch, P/Bag x1, Matieland 7602, South Africa

E-mail: Ike@sun.ac.za
During the past five decades, the world has seemed eager to occupy the moral high ground and offer endless international aid to try and help Africa as a whole to overcome its poverty. Africa south of the Sahara has in fact received more than US\$1 trillion in international aid over the past 50 years. In current monetary terms, that translates to US $\$ 5,000$ for every man, woman and child on the continent, yet numerous African countries today are worse off than they were 50 years ago (Oppenheimer, 2005). In fact, sub-Saharan Africa is the only region in the world where poverty has increased over the past decade. Between 1980 and 2002 the region's contribution to world trade, for example, was reduced by half. Against this background, the international community, through the United Nations Millennium Development Goals (United Nations, 2000), set targets for the eradication of extreme poverty. The Millennium Development Goals initiative provided one of the reasons Africa was given priority at the 2005 Gleneagles Summit of G8 countries, which responded with the Africa Action Plan in support of the New Partnership for Africa's Development (NEPAD) (G8 Gleneagles Africa, 2005).

The situation regarding poverty relief is not much different in South Africa even though the delivery of social services in the period since the first democratic elections of 1994 has seen a massive shift of fiscal resources to the poor (Van der Berg, 2004). Almost half the country's people live in poverty, with the poorest of the poor, an estimated 15 per cent of the population of 46.9 million (Statistics South Africa, 2005), struggling desperately to survive from day to day. The benefits of South Africa's democratic freedoms are passing them by. South Africa, together with Brazil, has the most uneven income distribution in the world with a Gini-coefficient (a measure of income inequality where 0 corresponds to perfect equality and 1 corresponds to perfect inequality) of 0.73 in 2001 (Landman, 2003). Yet the increase in the number of super-rich South Africans over a one-year period is matched only by Singapore, Hong Kong and Australia. More than half of Africa's dollar millionaires are based in South Africa (Piliso, 2005). Therefore, although many South Africans enjoy a higher standard of living than ever before, the poorest have become even poorer. In the formal sector it is estimated, for example, that unemployment rose from 20.2 per cent in 1970 to 26.1 per cent in 1994 and almost doubled to 45 per cent in 2002 (Scholtz, 2005). Although these unofficial figures differ substantially from the government's unemployment figures, Statistics South 
Africa reported that in 2001, 42.3 per cent of the population were not economically active (Statistics South Africa, 2005).

The poverty figures in South Africa should, however, also be appraised against government spending on social grants. To alleviate poverty in South Africa, an expanded safety net comprising 91 per cent of the social development welfare budget has been put in place (Dudley, 2004). About a quarter of the population receives social grants in some form or another, against only 4 per cent in comparable countries, such as Brazil or Mexico. That makes South Africa the country with the largest social welfare network outside Western Europe, at a cost of some 15 per cent of normal state expenditure (Buys, 2005).

Economic objectives cannot be achieved by depending on state funding alone. The South African government faces immense challenges and has made relative progress in eradicating poverty and inequality, mainly caused by underlying distortions in economic markets and social institutions introduced by apartheid which continue to produce and reproduce poverty and inequality in South Africa (May, 1998). The result is a constant tension between the government's social development goals and macro-economic vision for the country. In this context, Patel (2005: 118), a major architect of South Africa's developmental welfare system, concludes that 'The real issue for South Africa is how to combine social assistance with developmental strategies that will promote economic and social development through employment and social investment programmes that will build human capabilities to promote social and economic inclusion and reduce poverty.'

If the above conclusion were construed as a problem statement for social service delivery in South Africa, the following research question could be formulated based on the preceding context of this article: How might social workers in South Africa combat poverty, promote human growth and reduce social inequality? This question needs to be addressed within the context of South Africa adopting a social developmental welfare policy (Ministry for Welfare and Population Development, 1997). To this end, Midgley's (1995: 250) definition of social development as 'a process of planned social change designed to promote the wellbeing of the population as a whole in conjunction with a dynamic process of economic development' was used. According to Patel (2005: 29), a key assumption underpinning this approach was that 'economic development does not automatically translate into social improvements and that the benefits of growth do not reach all poor people equally'. Thus, it would seem that social investment in human development would address inequalities and distortions in development outcomes. This leads, however, to a further research question: How might social workers in South Africa combat poverty through the linking of human and economic development?
Clearly, for social workers the answer to this question does not lie in macro-economic solutions, for what impact could social workers, especially those working in non-governmental organisations, have on the country's macro economy? Social workers could possibly assist in promoting job creation and entrepreneurship (Lombard, 2003), but Patel (2005) rightfully asks whether such entrepreneurial activities might not divert organisations from their core services or distort the goals of voluntary organisations. By implication, job creation is a government responsibility.

\section{Social community education}

Closer to social work's traditional area of operation in linking human, social and economic development is the development of productive human resources, given that improved human productivity is regarded as a key to economic growth (Van Rooyen, 2005). In a modern economy, knowledge and skills development, attained through social development and education, is pivotal to productivity. In reality, social workers devote a great deal of their time to conveying information and providing social education to community members (Patel, 2005; Poetner, 1994). Though the ideals of community education are often aired in social work literature on empowerment and community work practice (Popple, 1996; Rothman \& Tropman, 1987; Weil \& Gamble, 1995; Weyers, 2001), the theoretical base for 'social community education' derives from Paulo Freire's (1972) work on 'popular education', which was widely adopted in Latin America in the 1970s. It has been developed mostly in the fields of adult education (Poetner, 1994) and liberation theology as a means of empowering marginalised and oppressed people. In this context the core elements of Freire's 'popular education' theory can be transposed to the South African situation.

Informal social community education is usually process driven and, as such, is situation specific, culturally relevant, responsive to local needs, and implies horizontal rather than top-down learning where the social worker works in partnership with the community. Rather than drawing on Marxist consciousness-raising discourse, as did Freire's work, andragogy or adult education is based on experiential learning theory (Engelbrecht, 2005) and a non-didactic pedagogy in which the participatory and dialogical aspects of the learning process are emphasised. More important than the gaining or 'banking' of knowledge is its utility and applicability: its transformative power and action orientation. Social workers have long been concerned with enhancing community, building social capital and effecting change in people's social conditions or quality of life. Paulo Freire was insistent that education must be situated in people's lived experience to enable them to imagine new possibilities, to generate 
new and empowering ways of naming things in their world, which would inspire action. This is why his approach has been especially effective in relation to literacy education and led to his method being referred to as a 'pedagogy of hope'. Thus, the core business of community education is to eliminate the disempowering effects of ignorance by improving the literacy and productivity of communities. Various forms of literacy exist, economic literacy amongst others. In this context economic literacy relates to the 'power of knowing' (Weyers, 2001: 162) by being literate in economic matters, such as understanding how the economy works and being able to participate in the economy through paid work.

\section{Economic literacy}

Economic literacy thus entails more than the ability to manage personal financial resources (South Africa President's Council Committee for Economic Affairs, 1993), though this is part of it, for through sound management of the household budget, the individual is able to make better day-to-day economic decisions. These are decisions not only about money, but also about resources and assets, e.g. being able to make informed decisions about products of financial institutions that will fit a transaction best, or being able to bargain for a better financial deal in a specific transaction, without being exploited. Economic literacy is thus a multi-dimensional concept that overlaps with various other concepts, such as consumer literacy and financial literacy, and as a category is related to the broader concept of 'money knowledge' (Piprek, Dlamini \& Coetzee, 2004). The essence of economic literacy is being informed and educated in economic decision making, in issues such as budgeting and understanding basic economic terms and concepts, such as profit, loss, interest, capital growth, scarcity, interaction of supply and demand and so on. For many people in South Africa, financial literacy and, by implication, economic literacy could be a means of escape from poverty (Piprek et al., 2004), and frontline social workers in community-based organisations offering generalist social work services are ideally placed to facilitate this type of education in a concrete and practical manner.

Clearly, those who are uneducated and illiterate are at a distinct disadvantage and are highly unlikely to gain easy access to the modern mainstream economy. The rapid transformation of the South African economy has left those disadvantaged by years of inadequate black education under apartheid to scrape together a livelihood in subsistence farming in rural areas and in the informal black economy in urban areas. The percentage of people employed in the formal sector in South Africa is still lowest in the black community (Statistics South Africa, 2004), and is reflected in the Gini-coefficient among blacks, which increased from 0.47 in 1975 to 0.66 in 2001 (Leibbrandt et al., 2004).
In short, social community education, as well as being an accepted social work task, is a recognised model of social work practice in South Africa and inevitably forms part of most community focused social work interventions (Van den Berg \& Weyers, 2004; Weyers, 2001). It is also clear that economic literacy as an aspect of money management is fundamental to the development of human capital (Piprek et al., 2004). In social development terms, it means linking social and economic development so that people can become active contributors to and participants in the mainstream economy. Social community education for economic literacy development is thus a social work initiative to link human and economic development, to promote human growth, to reduce social inequality and to foster sustainable social development.

\section{The research study}

The aim of the research study was to test the theoretical assumptions about social community education for economic literacy development (SCEELD) as outlined above. This provided empirical support for our attempt to construct a conceptual framework for the development of a SCEELD programme. The idea of SCEELD evolved from workshops conducted for social workers to explore their contribution to the war on poverty. SCEELD is thus not a concrete and developed programme that is currently being implemented by social workers, but rather an idea that needs to be theoretically conceptualised and empirically explored in order to construct a framework for the development of such a programme.

To accomplish this, the research focused on the social service delivery of frontline social workers in a non-governmental welfare organisation providing services to children and families in the Western Cape, one of South Africa's nine provinces. The aforementioned workshops served as a pilot study (Strydom, 2005) for the research and highlighted the efforts of social workers to educate clients of social work services through various economic literacy initiatives. The subsequent research examined the way in which social workers were linking human and economic development to combat poverty, promote human growth and reduce social inequality. The present case study explored the perceptions of social workers on their war on poverty and the challenges in constructing a conceptual framework for the development of a SCEELD programme.

This exploratory, descriptive study (Grinnell, Unrau $\&$ Williams, 2005; McMurty, 2005) used non-probability purposive sampling to identify ten frontline social workers as key informants (Schutt, 2005), i.e. those who were knowledgeable about the issues under investigation. Data collection was via semi-structured interviews (Gochros, 2005), which were transcribed and analysed 
in terms of dominant themes and coded accordingly. Every effort was made to preserve the qualitative aspects of the social workers' reflections since the main purpose was to learn from their experience in practice (Stake, 1995). To this extent, this might be seen as an instrumental case study facilitating a deeper understanding of the social issues concerned via the social workers' experience (Creswell, 1998; Delport \& Fouché, 2005; Fouché, 2005; Marshall \& Rossman, 1999).

\section{Sample profile}

The participants were professionally qualified social workers registered with the South African Council for Social Services Professions and each had more than eight years' practical experience in providing social work services in different contexts. They provided 'integrated social services' using developmental case, group and community work (see White Paper for Social Welfare, Ministry for Welfare and Population Development, 1997).

\section{Findings}

The social workers' reflections led to the identification of several themes relating to their understanding of poverty and the uneconomic activities of their clients, about which they were very knowledgeable. For the most part, it was found that their ideas about what needed to be done about this related very much to their attitudes towards poverty as the following discussion shows. Significantly, social workers did not think that job creation was their primary responsibility nor had, in their experience, job creation programmes been successful.

\section{Understanding of poverty and uneconomic activities of clients}

The social workers were asked about their views on the possible causes or origins of poverty of their clients. Generally, they viewed poverty from a 'minimalist' perspective, which is to say that they regarded people as poor if they lacked the absolute necessities, such as food, shelter and clothing. From their responses one might delineate four broad categories: (i) those with no income and no access to absolute necessities; (ii) those with no income and some access to minimal absolute necessities; (iii) those who receive state grants and have some access to minimal absolute necessities; and (iv) those who receive a minimum wage and have access to minimal absolute necessities.

Nevertheless, despite abject poverty measured against such social indicators, the African principle of ubuntu meant that clients were helped to survive through group or community solidarity. Ubuntu rests on group care rather than individual self-reliance (Smit \& Cronje,
1997). Thus, clients with minimal access to absolute necessities are cared for formally or informally by others with access to basic necessities, even if they themselves have limited means. Usually social workers encounter these people when they want to access formal state help, such as social grants, or when there are family or social problems, such as child abuse, rape or family violence and, increasingly, alcohol and drug abuse which is reaching epidemic proportions in the Western Cape and poses a serious challenge to poverty relief initiatives. However, these problems present symptoms of poverty, and usually call for crisis intervention.

Another major challenge is debt: clients borrow money excessively and incur debts that they are unable to manage. With easy access to credit, they purchase goods such as furniture and clothing they cannot afford and incur a huge burden of debt. Usually they do not realise or understand that borrowing entails interest. They also borrow money from micro-lending schemes and retail banks that target low-income groups. The social workers cited numerous examples where vulnerable clients had been misled and exploited by the sales techniques of businesses under the guise of assistance and service. A typical example is that of a well-known retail bank which focuses on black empowerment and accessibility by low-income groups. In its written advertisements the bank advertises its products in an idiom unfamiliar to the clients and a language with which they are not conversant. The bank is rather popular with the clients of social services, since it allows them to borrow substantial sums of money - more than at micro-lending agencies - without having to provide significant guarantees. The money is used to pay back other debts, or is simply spent with no thought at all to the interest payable. The social workers doubt their clients' ability to understand the economic terms or implications of their borrowing and spending patterns. Immediate gratification of pressing needs is their first priority. Eventually, the cycle of debt is beyond control and intensified by further indiscriminate buying, the rising cost of living, further additions to the family and other unplanned expenses.

At the point where these clients access social work intervention there is already an established culture of dependence: many clients are uneducated, have never worked and are long-term recipients of state grants. In fact, among clients, in most family systems there is at least one member who receives a social welfare grant, be it an old-age pension or a disability, foster care or child support grant. It is common practice among clients to use the grant allocated to a particular person in an extended family, e.g. a child support grant, to support an entire family. Thus, the grant is popularly referred to as 'Madiba money', Madiba being the affectionate name for Nelson Mandela, South Africa's icon of liberation from oppression. There are numerous instances of 
deliberate exploitation and abuse of the social security system. For example, teenagers fall pregnant on purpose to access 'Madiba money'. In general, there is a lack of hope for the future among the younger generation clients, many of whom receive social grants and have never worked, nor see any possibility of getting a job. They regard State financial assistance as an entitlement. This culture of shifting responsibility onto the government means that clients never have any savings; all available money is either lent, used to pay off loans or spent injudiciously. They never own assets, such as property, that increase in value. In fact, they have no understanding of economics at any level beyond cash in, cash out. They are, however, adept at surviving in this way, though one could hardly see this as financial planning and asset management. Their daily purchasing patterns reflect their 'economic illiteracy'. They tend to buy convenience foods and inferior products with appealing packaging or attractive pricing, thus incurring greater expenditure instead of looking for more economical alternatives, such as home cooking.

Often caregivers stop working when another family member, e.g. an older child, assumes the responsibility of income generation. In addition, caregivers spend inordinate amounts of money on cultural practices, such as christenings, weddings, initiation ceremonies, 21 st birthdays and funerals. Maintaining cultural ties is seen as infinitely more important than sound financial management and planning.

\section{Poverty relief initiatives}

The social workers' responses to the predicament described above depended largely on their value judgements regarding poverty. Most believed that job creation and concrete financial assistance or emergency feeding schemes would not necessarily alleviate poverty and improve economic literacy nor were such interventions necessarily sustainable. Most had participated in job creation programmes with minimal success since they are expensive to implement and involve risks for the service provider; they are resource intensive and add significantly to already overburdening workloads while their impact on the community is negligible. In fact, the social workers believed that job creation projects bring false hope; in any event, job creation was not their core business, largely because of their huge caseloads and primary statutory child protection responsibilities.

The social workers believed that there was no clear mandate as to their role in social service delivery to clients living in poverty. In relation to improving economic literacy they could fulfil (i) an advocacy role and help clients pay their debts or pay less in school fees; (ii) a role of facilitator-coordinator by bringing social work clients and businesses together so that entrepreneurial skills might be imparted; (iii) a networking role establishing networks and partnerships, and introducing clients to available resources.

\section{Developing economic literacy}

How do social workers then contribute to economic literacy? This role requires that social workers (i) enable clients to turn economic processes to their advantage; (ii) educate them to take control of their income and gain access to absolute necessities no matter how meagre they might be; (iii) arm them with economic wisdom; (iv) conduct multidimensional assessments of clients' level of economic literacy; and (v) identify positive strategies, using commonsense economic terms, aimed at economic literacy.

Participatory educational or experiential learning techniques, such as workshops, socio-drama, visual aids, interactive demonstrations, games and role-plays, are employed by the social workers. Skills development through demonstration and role-playing is more important than just imparting knowledge or information. For example, instruction in how to prepare cheap wholesome meals involves shopping for the ingredients, comparing prices, examining goods for quality and nutritive value, preparing and cooking the food, and reflecting on lessons learnt about planning and budgeting.

The social workers believed that, as with all kinds of literacy, the skills clients gained while developing economic literacy must be practised. Therefore, to have an impact, these economic literacy initiatives cannot be just once-off occurrences, but must rather be processes integrated with the social workers' interventions on an individual, family, group and community level - in other words it could be, but is not necessarily, an additional intervention. However, the problems that the clients presented constituted, in most cases, the social workers' primary area of intervention, with the development of economic literacy as a 'by-product' of their intervention.

\section{Social Community Education for Economic Literacy Development (SCEELD)}

Subsequently a conceptual framework for the development of a SCEELD programme (as indicated in italics below) will be constructed and examined against the findings from the social workers:

\section{Social workers should consciously employ SCEELD} in their generalist social work practice with a vision to linking human and economic development, promoting human growth and reducing social inequality in order to foster sustainable social development.

From our findings, we can see that social workers do not talk in these terms at all and are highly sceptical of their role in promoting economic development, which they interpret mainly as job creation. Their focus is a 
housekeeping one - such as the better management of the meagre resources clients have.

2. The goal of SCEELD should be to enable clients of social work services who live in poverty to exploit economic processes to their own advantage, so that they can take control of their income and absolute necessities that they do indeed have access to.

Here, the social workers identified several roles, namely, advocate, facilitator, coordinator and networker. They saw their role as intermediary rather than direct intervention.

3. The objectives of SCEELD should be inhibiting notions of entitlement and the dependence on others and facilitating a productive vision and hope for the future in which people living in poverty will be able to take informed and advantageous economic decisions.

Given the way in which developmental welfare policy is being implemented, i.e. mainly through social grants, the social workers were highly sceptical of any tangible gains being made in reducing dependency. If anything, a culture of dependency has become more deeply entrenched by 'Madiba money'.

4. The guiding principle of SCEELD should be that social workers need to be intimately familiar with and attuned to the poverty aetiology of their social work clients in order to be able to transpose relevant economic concepts to the life world of the client in a consciousness-raising way that is typically nonformal, in partnership with the community and from a people-centred perspective.

The social workers' attitude to poverty determined their views on intervention; overall they did not believe that economic development was part of the social work task. None talked specifically about the relationship between social and economic development. There were only a few examples of community partnerships, and none talked about 'consciousness-raising' or 'peoplecentred development'. Social workers were more concerned with dealing with problems as they presented themselves. It was thus not clear whether they had any conception of their work being developmental in keeping with the philosophy of the White Paper for Social Development (Ministry for Welfare and Population Development, 1997).

5. SCEELD should be integrated practically and consciously by social workers, fulfilling the role of economic literacy educator supplementary to the roles they fulfil in all social work methods at all levels of social work intervention.

Counselling about budgeting and the management of meagre resources takes a secondary place to helping people gain access to resources, such as grants or concrete assistance. This is why clients come to see social workers and this is what they want. Social supports are available in their communities and the principle of ubuntu is working relatively well.

6. SCEELD needs to be operationalised as a process through experimental education on the basis of andragogical and pedagogical educational principles in order to allow economic literacy to be practised as a skill within the frame of reference of the client.

Generally, social workers are comfortable with participatory strategies and are familiar with experiential learning techniques as these form part of their daily work.

7. SCEELD should be regarded as a long-term investment in human capital for the benefit of the next generation.

The social workers supported this in principle, although there was little evidence that they deliberately focused their energy on younger people. More often than not, social workers' contacts are with the females of the household who are mainly involved with the care of their children. Thus, indirectly, educating mothers means educating children.

8. Social workers should consciously develop their own knowledge, attitudes and skills when employing SCEELD.

This will only happen in a culture where social workers are expected to perform and are rewarded for this work. When it is only a small part of what they do, and seen as time and resource intensive given their heavy workloads, they can do little more than attend to these matters as they arise in each individual case.

9. Further research is required to develop the content of and to operationalise this conceptual framework of SCEELD into a poverty alleviation programme that takes the practical realities for social workers into account.

Many questions evolve from this study: What is the role social workers play in poverty alleviation? Do they work to eradicate poverty or just help people live with it? How do social workers make the switch to implement programmes like SCEELD so that they are working towards long-term goals of poverty eradication and not just providing short-term responses to clients presenting problems that take up all their time? On the basis of this study as a reflection of the practice reality, it is currently unlikely that a developed SCEELD programme would be successful because social workers need an agency culture that would enable them to dedicate time and energy to implement poverty alleviation programmes. Thus, to develop the content of a SCEELD programme and to operationalise it, several social workers at an agency could be dedicated to work on a trainer 
model in order to ensure the success of such a programme. These social workers must be properly trained to educate people to become economically literate. In this way social workers might take up the challenge to address poverty, in this instance by helping clients to become 'economically literate' and, in so doing, preparing them to participate in public works or other initiatives aimed at job creation: social workers do not have to create jobs, but they can facilitate and prepare clients for them.

\section{Conclusion}

When juxtaposing the findings of this research with research and practices in other sectors of economic and social development in South Africa (Lombard, 2003; Piprek et al., 2004), it is imperative to note that this study was commissioned partly because of a statutory agency's interest in promoting a social development agenda, with a particular focus on economic empowerment. Some social workers in other sectors might indeed be more deeply engaged in, and successful at, community-based economic empowerment. The focus of this article, however, is the core business and mindset of a particular group of social workers. Wider research on this issue is needed so as to inform social work education and improve its responsiveness to practice.

According to popular education theory, by developing people's literacy, and by implication their economic literacy, they can be helped to escape from poverty and become productive contributors to, and participants in, the mainstream economy. This article has described an exploratory study which sought to find empirical support for the claim that social community education is an accepted model of generalist social work, particularly in community practice in South Africa (Weyers, 2001). While, in theory, 'social community education' might be useful for the development of economic literacy as part of social workers' war on poverty, there are many challenges to its implementation, not least social workers' attitude towards social development, which the participant social workers tended to equate with job creation. Importantly, they did not see this as a primary social work function nor did they see the agency's culture and purpose as conducive to such work. Overall, there was little evidence that the participant social workers were doing developmental social work. It seems that social workers in general are so caught up with trying to deal with clients' presenting problems that there has been little conscious effort to develop their economic literacy, except as a by-product of 'normal' casework intervention. Is this the most that can be expected from social workers? Are small gains worthwhile, and do they collectively add up to social improvement? Social workers offer social support and access to social resources where available and, in this way, fight the war on poverty and contribute to uplifting the country's poor. Is this enough?

\section{References}

Buys F (2005). Belastingstelsel verarm werkendes [Tax system impoverishes working people]. Rapport 17 July.

Creswell JW (1998). Qualitative inquiry and research design: Choosing among five traditions. Thousand Oaks, Sage.

Delport CSL, Fouché CB (2005). The qualitative research report. In: De Vos AS, ed. Research at grass roots: A primer for the caring professions. Pretoria, Van Schaik.

Dudley C (2004). Social Services NGO funding. African Christian Democratic Party Speeches. Available at http://www.acdp.org.za/ speeches.asp?show $=$ speech36.txt $[$ date last accessed 12 September 2005].

Engelbrecht LK (2005). Perspectives on the community education model of social work: Implications for education and practice. Social Work/Maatskaplike Werk 41: 143-154.

Fouché CB (2005). Qualitative research designs. In: De Vos AS, ed. Research at grass roots. A primer for the caring professions. Pretoria, Van Schaik.

Freire P (1972). Pedagogy of the oppressed. London, Penguin Books.

G8 Gleneagles Africa (2005). Available at: http://www.g8.gov.uk/ servlet/Front?pagename $=$ OpenMarket/Xcelerate/Showpage\&c $=$ page\&cid=1094235520151 [date last accessed 5 August 2005].

Grinnell RM, Unrau YA, Williams M (2005). Scientific inquiry and social work. In: Grinnell RM, Unrau YA, eds. Social work research and evaluation. Quantitative and qualitative approaches, 7th edn. Oxford, Oxford University Press.

Gochros H (2005). Interviewing. In: Grinnell RM, Unrau YA, eds. Social work research and evaluation. Quantitative and qualitative approaches, 7th edn. Oxford, Oxford University Press.

Landman JP (2003). Breaking the grip of poverty and inequality in South Africa, 2004-2014. Current trends, issues, and policy options. Pretoria. Unisa. Available at: http://www.sarpn.org.za/ documents/d0000649/P661-Povertyreport3b.pdf [date last accessed 5 August 2005].

Leibbrandt M, Poswell L, Naidoo P, Welch M, Woolard I (2004). Measuring recent changes in South African inequality and poverty using 1996 and 2001 Census data. Centre for Social Science Research. CSSR working paper no.84. Rondebosch, University of Cape Town.

Lombard A (2003). Entrepreneurship in Africa: Social work challenges for human, social and economic development. Social Work/Maatskaplike Werk 39: 224-239.

Marshall C, Rossman GB (1999). Designing qualitative research, 3rd edn. London, Sage.

May J ed. (1998). Poverty and Inequality in South Africa. Report prepared for the Office of the Executive Deputy President and the Inter-Ministerial Committee for Poverty and Inequality. Praxis Publishing. Durban. Available at: http:// www.welfare.gov.za/Documents/1998/Pov.htm [date last accessed 5 August 2005].

McMurty SL (2005). Surveys. In: Grinnell RM, Unrau YA, eds. Social work research and evaluation. Quantitative and qualitative approaches, 7th edn. Oxford, Oxford University Press.

Midgley J (1995). Social development: The developmental perspective in social welfare. London, Sage.

Ministry for Welfare and Population Development (1997). White Paper for Social Welfare. Notice 1108 of 1997. Government Gazette, Vol. 386, No. 18166. Pretoria, South Africa, Government Printer.

Oppenheimer N (2005). Afrika verdien meer [Africa deserves more]. Die Burger 16 July. 
Patel L (2005). Social welfare and social development in South Africa. Cape Town, Oxford South Africa.

Piliso S (2005). SA's wealth explosion. Sunday Times 17 July.

Piprek G, Dlamini P, Coetzee G (2004). Financial Literacy Scoping Study and Strategy Project. Final Report. FinMark Trust. ECIAfrica Consulting (Pty) Ltd. Available at ftp://ftp.fsb.co.za/ public/Consumer\%20Education/FinLit_\%20Report.pdf [date last accessed 13 December 2006].

Poetner J (1994). Popular education in Latin America: a technology for the North? International Social Work 37: 265-275.

Popple K (1996). Community work: British models. Journal of Community Practice 3: 147-180.

Rothman J, Tropman JE (1987). Models of community organization and macro practice perspectives: Their mixing and phasing. In: Cox FM, Erlich JL, Rothman J, Tropman JE, eds. Strategies of community organization, 4th edn. Itasca, Peacock Publishers, Inc.

Scholtz L (2005). The political and socio-economic framework of the New South Africa. Paper presented at the Association of South African Social Work Education Institutions annual conference (ASASWEI), 6-7 September 2005, University of Stellenbosch, Stellenbosch.

Schutt RK (2005). Sampling. In: Grinnell RM, Unrau YA, eds. Social work research and evaluation. Quantitative and qualitative approaches, 7th edn. Oxford, Oxford University Press.

Smit PJ, Cronje GJ, eds. (1997). Management principles. A contemporary edition for Africa, 2nd edn. Kenwyn, Juta and Co, Ltd.

South Africa President's Council Committee for Economic Affairs (1993). Report of the Committee for Economic Affairs on the Promotion of Economic Literacy. Pretoria, Government Printers.
Stake R (1995). The art of case study research. Thousand Oaks, Sage.

Statistics South Africa (2004). Labour Force Survey. Statistical release PO210. Available at www.statssa.gov.za [date last accessed 27 September 2006].

Statistics South Africa (2005). Achieving a better life for all. Progress between Census '96 and Census 2001. Report no. 03-02-16. Available at www.statssa.gov.za [date last accessed 28 September 2005].

Strydom H (2005). The pilot study. In: De Vos AS, ed. Research at grass roots. A primer for the caring professions. Pretoria, Van Schaik.

United Nations (2000). United Nations Millennium Declaration. Resolution adopted by the General Assembly (A/55/L.2).

Van den Berg AM, Weyers ML (2004). Die gemeenskapswerkdienste van die private welsynsektor: " $n$ profiel met implikasies [The community work services of the private welfare sector: a profile with implications]. Social Work/Maatskaplike Werk 40: 344-365.

Van der Berg S (2004). Poverty, inequality and social delivery: Had democracy brought progress? Paper delivered to BER Conference on Outlook for the South African Economy, 18th June 2004, Santon, South Africa.

Van Rooyen D (2005). Produktiwiteit kan Afrika heel [Productivity can heal Africa]. Rapport 7 August.

Weil M, Gamble DN (1995). Community practice models. In: Edwards RL, ed. Encyclopaedia of Social Work, 19th edn. Washington, DC, NASW.

Weyers ML (2001). The theory and practice of community work: A South African perspective. Potchefstroom, Keurkopie. 